
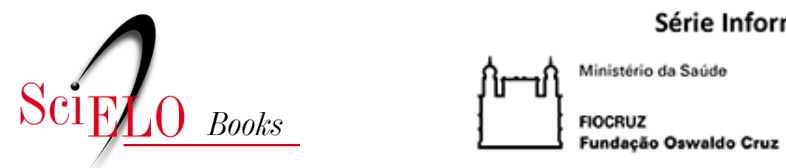

OBSERVATÓRIO COVID-19

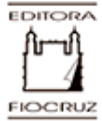

Parte I - Cenários

\title{
8. A Pandemia pelo Sars-CoV-2 no estado do Amazonas
}

José Joaquín Carvajal Cortés

Fernando José Herkrath

Sérgio Luiz Bessa Luz

Marcelo Ferreira da Costa Gomes

Christovam Barcellos

Leonardo Soares Bastos
Bernardino Cláudio de Albuquerque

Felipe Gomes Naveca

Rodrigo Tobias de Sousa Lima

Daniel Antunes Maciel Villela

Carlos Machado de Freitas

Margareth Crisóstomo Portela

Valcler Rangel Fernandes

\section{SciELO Books / SciELO Livros / SciELO Libros}

CORTÉS, J. J. C., ALBUQUERQUE, B. C., HERKRATH, F. J., NAVECA, F. G., LUZ, S. L. B., LIMA, R. T. S., GOMES, M. F. C., VILLELA, D. A. M., BARCELLOS, C., FREITAS, C. M., BASTOS, L. S., PORTELA, M. C., and FERNANDES, V. R. A Pandemia pelo Sars-CoV-2 no estado do Amazonas. In: FREITAS, C. M., BARCELLOS, C., and VILLELA, D. A. M., eds. Covid19 no Brasil: cenários epidemiológicos e vigilância em saúde [online]. Rio de Janeiro: Observatório Covid-19 Fiocruz; Editora Fiocruz, 2021, pp. 143-158. Informação para ação na Covid-19 series. ISBN: 978-65-5708-049-8. https://doi.org/10.7476/9786557081211.0009.

\section{(c) (1)}

All the contents of this work, except where otherwise noted, is licensed under a Creative Commons Attribution 4.0 International license.

Todo o conteúdo deste trabalho, exceto quando houver ressalva, é publicado sob a licença Creative Commons Atribição 4.0.

Todo el contenido de esta obra, excepto donde se indique lo contrario, está bajo licencia de la licencia Creative Commons Reconocimento 4.0. 


\title{
A Pandemia pelo Sars-CoV-2 no Estado do Amazonas
}

\author{
José Joaquín Carvajal Cortés, Bernardino Cláudio de Albuquerque, \\ Fernando José Herkrath, Felipe Gomes Naveca, Sérgio Luiz Bessa Luz, \\ Rodrigo Tobias de Sousa Lima, Marcelo Ferreira da Costa Gomes, \\ Daniel Antunes Maciel Villela, Christovam Barcellos, \\ Carlos Machado de Freitas, Leonardo Soares Bastos, \\ Margareth Crisóstomo Portela e Valcler Rangel Fernandes
}

A

resposta à introdução e difusão do Sars-CoV-2 no estado do Amazonas seguiu-se à concepção dominante no país e no mundo de que esse seria mais um problema de saúde pública, visto como de impacto moderado, transitório e solucionável com a implementação de estratégias e ações de intervenção - portanto, sem grandes repercussões nas condições de vida da população. Infelizmente, o problema não foi considerado como o grande desafio sanitário que é, apesar de todos os indicadores sinalizarem nessa direção: o desconhecimento do agente e de sua dinâmica de transmissão, sua virulência, fisiopatogenia, biologia e imunologia, aliado à sua alta transmissibilidade e disseminação.

A suscetibilidade universal da população humana ao patógeno foi considerada com limitações, assim como o fato de que a proteção e preservação da vida exigiam também a produção do conhecimento sobre todas as etapas da história natural da Covid-19. Esperou-se acontecer, mesmo reconhecendo-se que poucas armas estariam disponíveis para a prevenção e quase nenhuma direcionada à preservação da vida. As perspectivas se mostraram sombrias: inexistência de tratamento específico, restrição de testes para diagnóstico, escassez de insumos laboratoriais e hospitalares, de equipamentos e de toda uma infraestrutura hospitalar necessária à assistência aos pacientes. Aliadas a todos esses fatores, ressaltam-se a reduzida experiência das equipes de saúde no manejo 
da atenção básica perante a doença e a baixa capacidade de implementar ações coletivas para restringir a velocidade de disseminação do vírus.

Não foi difícil imaginar esse cenário em um território de 1.570 .745 quilômetros quadrados, no qual as dimensões dos 62 municípios ultrapassam a área de inúmeros países. O acesso à capital por via terrestre é viável somente para 12 municípios do estado; para os demais a grande via de acesso é a malha fluvial, em que o tempo de deslocamento, em sua grande maioria, é mensurado em dias ou semanas. O sistema de saúde é configurado pelas regiões de saúde que, em termos operacionais, não desempenham satisfatoriamente esse papel, uma vez que grande parte da atenção secundária e terciária tem como única referência a capital, Manaus. Ademais, o estado do Amazonas alberga grupos populacionais extremamente vulneráveis e susceptíveis, como populações indígenas e populações ribeirinhas, ambas também ocupando áreas remotas e de difícil acesso. O estado conta com a maior população indígena em números absolutos no país: o Censo Demográfico do IBGE 2010 identificou 65 grupos indígenas no Amazonas, perfazendo um total de 168.680 indígenas, sem considerar grupos ainda não contatados, presentes em vales de grandes rios como o do rio Javari.

Nesse cenário, somente após a Organização Mundial da Saúde (OMS) ter declarado situação de Emergência de Saúde Pública de Importância Internacional (Espii), em 30 de janeiro de 2020, e o Estado brasileiro ter declarado Emergência em Saúde Pública de Importância Nacional (Espin), em 3 de fevereiro de 2020, foi criado no Amazonas o Centro de Operações de Emergência para o enfrentamento da Covid- 19 (COE-AM), no âmbito da Fundação de Vigilância em Saúde do Amazonas. Em 26 de fevereiro de 2020 foi confirmado o primeiro caso de Covid-19 no país e em 13 de março de 2020 o primeiro caso no estado do Amazonas, após o que foi decretado, em 16 de março de 2020, o Estado de Emergência em Saúde Pública no Amazonas (Manaus, 2020; Amazonas, 2020a). A partir daí o COE-AM foi reconfigurado e ampliado, com a participação de instituições representadas como possíveis interfaces no enfrentamento da situação (Amazonas, 2020b).

Nessa fase inicial, a doença teve como epicentro a capital, Manaus, com reconhecimento da transmissão comunitária em 28 de março de 2020. A difusão para os municípios foi rápida, não obedecendo à contiguidade e dispersando-se em focos para várias regiões do estado. A partir de então, o número de casos e óbitos teve crescimento exponencial, tanto na capital quanto na grande maioria dos municípios do interior. Em 30 de março o registro de casos confirmados no estado era de 229, com 205 notificados na capital. Um mês depois, em 30 de abril, o número de casos acumulados era de 5.254, 
evidenciando um acréscimo de $2.194 \%$ em relação a 30 de março; a capital demonstrou um crescimento percentual de $1.496 \%$ e o conjunto dos demais municípios, de $8.154 \%$. No dia 18 de maio, o número de casos confirmados em municípios do interior ultrapassou o registro da capital, situação que persiste até o momento. Decorridos nove meses de epidemia (20 de dezembro de 2020), o estado registrou 191.976 casos confirmados e 5.085 óbitos por Covid- 19 (FVS-RCP, 2020).

Durante esse período foram vivenciados momentos difíceis, caracterizados pelo rápido e expressivo aumento no número de casos e de óbitos na capital e em municípios do interior, com grave colapso da rede de atenção à saúde e do sistema de destinação final de corpos daqueles vitimados pela doença. Manaus passou a ocupar a mídia nacional e internacional em razão do estado de calamidade instalado, apresentando à época as maiores taxas de incidência e mortalidade por Covid- 19 dentre as capitais. Posteriormente, em função das medidas de contenção adotadas e da melhora relativa da adesão da população às medidas não farmacológicas preconizadas, associadas a uma diminuição da população suscetível, a curva de ocorrência de casos e de óbitos entrou em declínio, mantendo-se, porém, estacionada em patamares ainda preocupantes, demonstrando nos últimos meses oscilações com recrudescência.

Propomo-nos, aqui, a analisar a evolução da Covid- 19 no território amazônico, observados os aspectos da distribuição da doença na capital e de regiões de saúde do estado do Amazonas, o mapeamento de casos na região de tríplice fronteira internacional e a caracterização genética do vírus ao longo do ano de 2020. Para isso, estruturamos o capítulo em três partes: na primeira apresentamos uma análise da historicidade das doenças respiratórias de notificação compulsória, na segunda mapeamos o desenvolvimento da pandemia no interior do estado e zona de fronteira e na terceira discorremos sobre a caracterização molecular do vírus.

\section{ANÁLISE DA NOTIFICAÇÃO DA SÍNDROME RESPIRATÓRIA AGUDA GRAVE NAS REGIÕES DE SAÚDE DO ESTADO DO AMAZONAS}

Dados nacionais da vigilância de síndrome respiratória aguda grave (Srag) notificados no sistema Sivep Gripe e processados pelo InfoGripe permitem verificar padrões distintos entre os gráficos de série temporal da capital, Manaus, e aqueles das regiões de saúde do estado do Amazonas (Fiocruz, 2020a). Observam-se também diferenças na semana epidemiológica de notificação dos primeiros casos e nas incidências máximas notificadas (Figura I). Para permitir uma avaliação adequada, o município de Manaus foi analisado separadamente da sua região de saúde (Entorno de Manaus e Alto Rio Negro). 
As epidemias propagadas, ou seja, transmitidas de pessoa para pessoa, podem durar mais do que as epidemias de fonte comum e se caracterizar por várias elevações na incidência de casos por 100 mil habitantes (Torok, 2020). Quanto à magnitude da epidemia, observa-se que o município de Manaus e as regiões do Entorno de Manaus e Alto Rio Negro e Alto Solimões, que inclui a região da tríplice fronteira Brasil-ColômbiaPeru, apresentaram os picos com maiores incidências de casos notificados por 100 mil habitantes. Cavalcante e colaboradores (2020) mostraram que até a $20^{\text {a }}$ semana epidemiológica o Amazonas apresentava a maior taxa de incidência da Covid- I 9 das unidades federativas do país, bem como a maior taxa de mortalidade. Verifica-se, ainda, que algumas regiões, como Entorno de Manaus e Alto Rio Negro, mantiveram elevada notificação de casos de Srag após o período de incidência máxima.

Figura 1 - Casos notificados e estimados de síndrome respiratória aguda grave (Srag) nas regiões de saúde do Amazonas e em Manaus segundo a semana epidemiológica, por município de notificação do caso - Semanas epidemiológicas de I a 50 de 2020
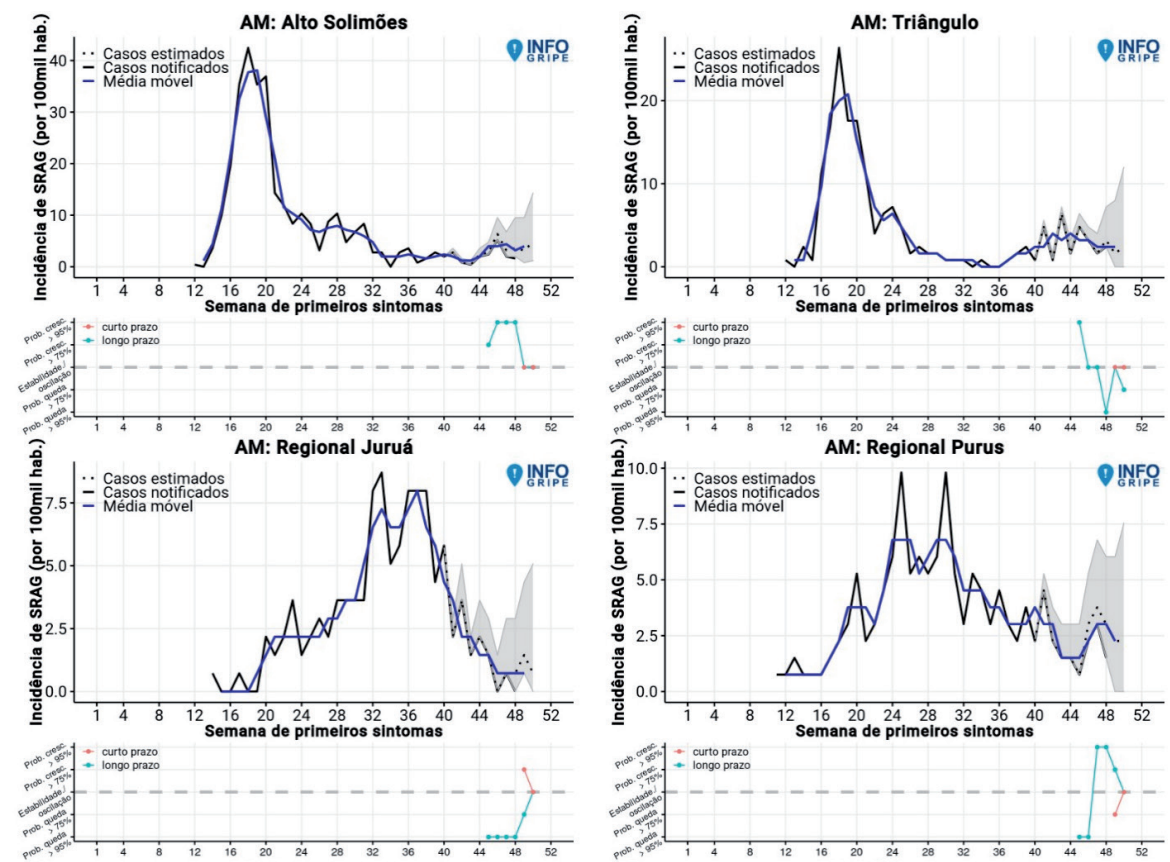
Figura I - Casos notificados e estimados de síndrome respiratória aguda grave (Srag) nas regiões de saúde do Amazonas e em Manaus segundo a semana epidemiológica, por município de notificação do caso - Semanas epidemiológicas de I a 50 de 2020 (continuação)
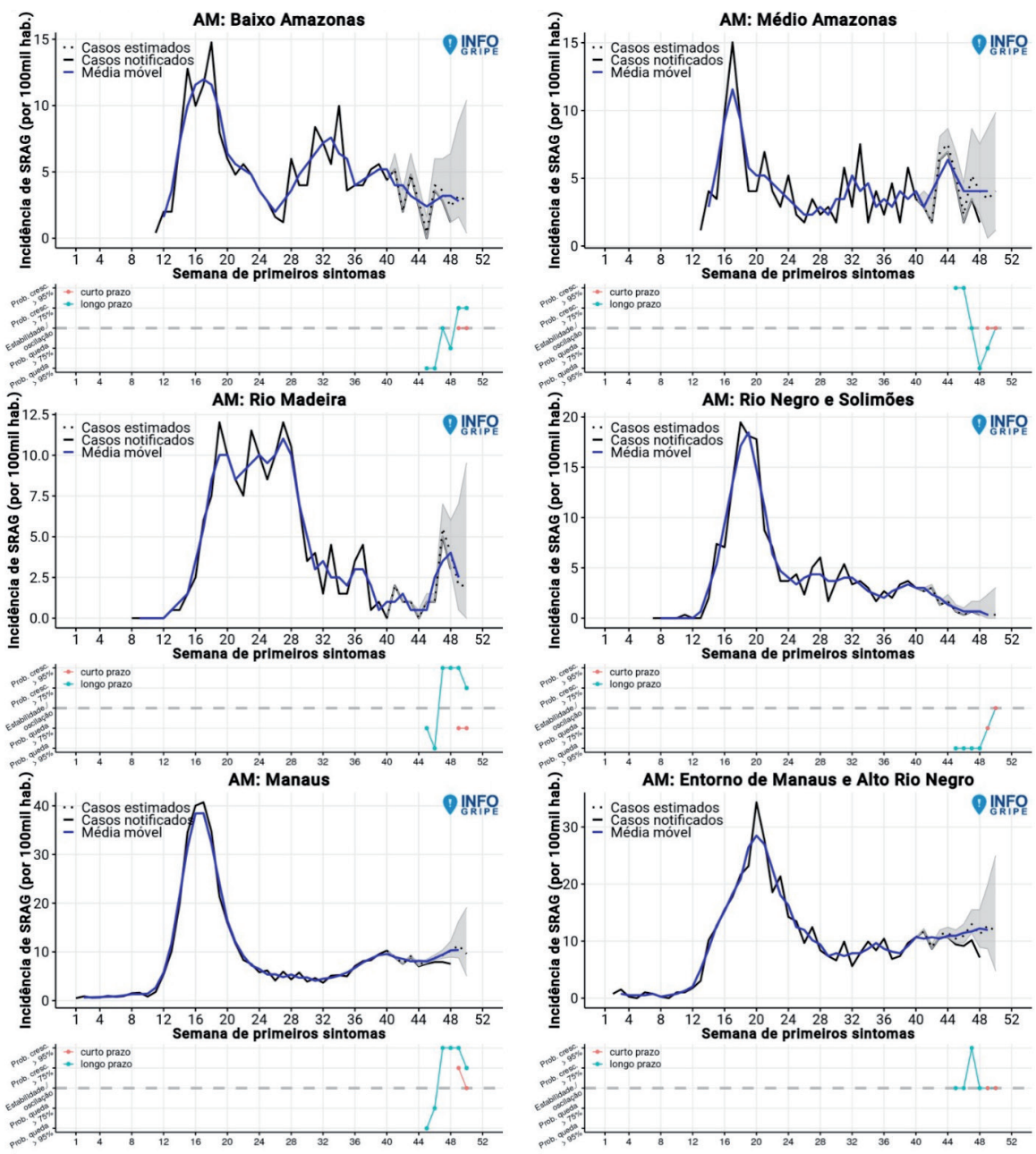

Fonte: InfoGripe - Sivep Gripe; GT Influenza (SVS/MS). 
Os gráficos também mostram que algumas regiões de saúde apresentaram notificação tardia dos primeiros casos, em especial a região do Juruá, que abrange municípios de difícil acesso. $\mathrm{Na}$ análise do comportamento das curvas epidêmicas segundo as regiões de saúde do Amazonas, identificam-se três padrões de curva principais, a saber:

I. Regiões de saúde com curva de crescimento exponencial e contínuo da taxa de incidência de casos, com posterior decréscimo em ritmos variáveis, porém mantendo uma cauda de curva em diferentes patamares de transmissão e em processo de aumento, estabilização ou queda. Esse padrão pode indicar que a epidemia seguiu seu curso natural, com baixa interferência das medidas de contenção adotadas. Representado pelo município de Manaus e regionais: Rio Negro e Solimões, Médio Amazonas, Alto Solimões, Triângulo e Entorno de Manaus e Alto Rio Negro.

2. Regiões de saúde com curva de crescimento de forma mais moderada e descontínua da taxa de incidência de casos, intercalando picos e decréscimos de seus níveis, mantendo-se em diferentes patamares de transmissão e em processo de recrudescimento, estabilização ou queda. Esse comportamento está possivelmente associado à adoção de medidas locais de contenção, com alguma efetividade, em períodos distintos, pelos municípios que as compõem. Representam esse comportamento as regiões de saúde do Rio Madeira e Baixo Amazonas.

3. Regiões com crescimento da taxa de incidência de casos de forma lenta, possivelmente traduzindo maiores restrições de acesso e menor mobilidade populacional, resultando em menor pressão de introdução do vírus. Esse padrão é representado pelas regiões de saúde do Rio Purus e do Rio Juruá, que compreendem alguns dos municípios de mais difícil acesso no estado. Em contrapartida, vale destacar as altas condições de receptividade à reprodução viral dessas áreas, decorrentes de precárias condições socioeconômicas, alta concentração de população indígena e outros grupos vulneráveis, dificuldades logísticas e nas condições de atenção à saúde, o que pode incluir ainda problemas para a testagem dos casos suspeitos e possíveis atrasos na notificação.

Compreender as características epidemiológicas da transmissão de Covid-19 é essencial para formular estratégias eficazes de controle. Análise das curvas de quatro países relacionadas à epidemia de Sars em 2003 mostrou a importância da implementação rápida de medidas de controle para limitar o impacto da epidemia, com redução tanto 
dos casos quanto do período de vigência de medidas mais restritivas de controle da infecção (Wallinga $\varepsilon$ Teunis, 2004). Cabe ressaltar, no entanto, que os dados de recortes territoriais amplos, como as regiões de saúde, podem dificultar a avaliação de heterogeneidades nos municípios que as compõem.

A Figura 2 mostra a taxa de incidência acumulada até a semana epidemiológica 50, calculada a partir das notificações de síndromes respiratórias por município de notificação; no entanto, é importante lembrar que os casos confirmados dependem da confirmação laboratorial, o que nem sempre está disponível no município.

Figura 2 - Taxa de incidência acumulada de casos confirmados de Covid- 19 por município de notificação do estado de Amazonas - Semanas epidemiológicas de I a 50 de 2020

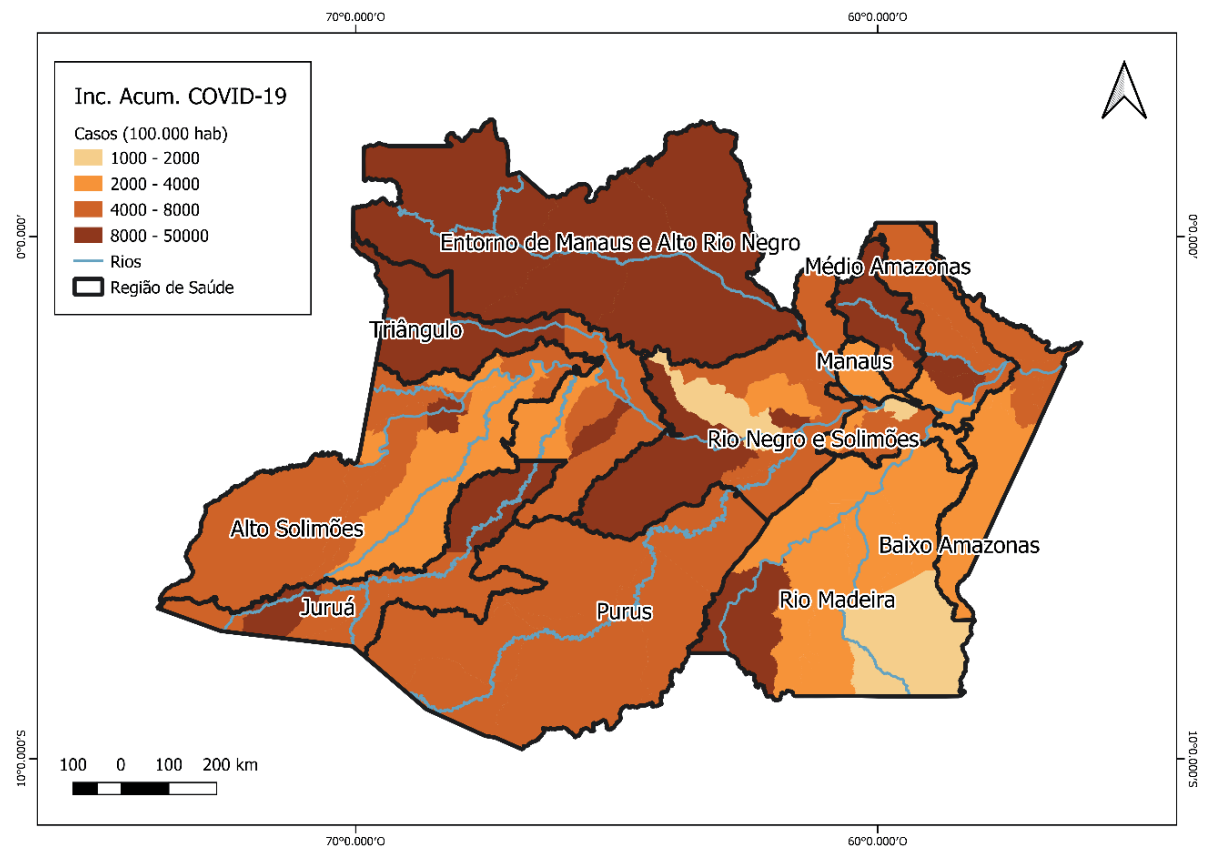

Fonte: Cievs/FVS-AM. Datum Sirgas 2000 (EPSG: 4674). Elaborada por José Joaquín Carvajal Cortés (ILMD/Fiocruz Amazônia) em 17 dez. 2020.

Quanto à sua distribuição espacial, podem-se observar alguns clusters de maior incidência de casos, nas regionais de Entorno de Manaus e Alto Rio Negro, Baixo Amazonas, Médio Amazonas, Triângulo e Juruá, destacando-se com maior incidência acumulada os municípios de Japurá, Itapiranga, Carauari, São Gabriel da Cachoeira, 
Barcelos, Presidente Figueiredo, Coari, Santa Isabel de Rio Negro e Amaturá, associados principalmente às hidrovias dos rios Solimões e Amazonas e seus afluentes.

É importante atentar para o comportamento heterogêneo da taxa de incidência e mortalidade acumulada nos diferentes recortes geográficos. O estado tem uma taxa de incidência de 4.507,7 casos/100 mil habitantes, sendo que na capital esta é de 3. 187/100 mil habitantes e para o conjunto dos 61 municípios do interior de 5.7 15/100 mil habitantes. Com relação à mortalidade, a taxa para o estado é atualmente de 122,2 óbitos/100 mil habitantes, para a capital, de 146,01 e para o interior, de 92,46. Com base nos indicadores por regionais de saúde, verifica-se que a regional do Juruá é a detentora da maior taxa de incidência acumulada (8.423,6 casos/1 00 mil habitantes), contrastando com a menor taxa de mortalidade (50,8/I00 mil habitantes). A menor incidência foi detectada na regional do Entorno de Manaus e Alto Rio Negro, com 3.9 I 0,3 casos/ I 00 mil habitantes, porém com elevada taxa de mortalidade, I39,3 óbitos/ / 00 mil habitantes (FVS-RCP, 2020).

\section{DINÂMICA EPIDEMIOLÓGICA DA COVID-19 NA ZONA DE FRONTEIRA ENTRE BRASIL, COLÔMBIA E PERU}

A zona de fronteira entre Brasil, Colômbia e Peru (tríplice fronteira amazônica) compreende as três faixas de fronteira de cada país: I) Faixa de fronteira brasileira - Arco Norte, sub-região III (Parima-Alto Rio Negro), IV (Alto Solimões), V (Alto Juruá) e VI (Vale do Acre - Purus) da faixa de fronteira brasileira; 2) Faixa de fronteira colombiana - Departamentos do Amazonas, Guainía, Putumayo e Vaupés e; 3) Faixa de fronteira peruana - Departamentos de Loreto, Madre de Dios e Ucayali (Pêgo et al., 2017). Para a elaboração desta seção, os dados de vigilância de casos confirmados e óbitos pela Covid- 19 foram analisados por município, distrito ou corregimento dos estados e departamentos fronteiriços de cada país,' publicados pelas instituições oficiais, em colaboração com a Rede Transfronteiriça para o Enfrentamento da Covid- 9 na Tríplice Fronteira entre Brasil, Colômbia e Peru (Fiocruz, 2020b), no período entre 13 de março e 17 de dezembro de 2020.

Na Amazônia, região transfronteiriça, a disseminação do Sars-CoV-2 até dezembro de 2020 foi acelerada desde o primeiro caso confirmado no município de Manaus, AM (Brasil), no dia 13 de março. Nove meses depois, a doença se disseminou em 94,7\%

I Colômbia: Vigilancia em Salud Pública/Secretaría de Salud Departamental del Amazonas (VSP Amazonas); Peru: Dirección Regional de Salud del Departamento de Loreto (Diresa Loreto); Brasil: Centro de Informações Estratégicas de Vigilância em Saúde (Cievs/FVS-AM). 
( 16 I/I 70) dos municípios da região de fronteira entre Brasil (BR), Colômbia (CO) e Peru (PE): em 100\% (62/62) dos municípios do estado do Amazonas-BR, I00\% (53/53) dos distritos de Loreto-PE e 83,6\% (46/55) dos municípios dos departamentos amazônicos da Colômbia. Quanto à evolução da disseminação do vírus, mais da metade dos municípios no estado do Amazonas no Brasil já havia confirmado casos de Covid- 19 em abril, seguidos de Peru em maio e Colômbia em julho (Carvajal-Cortés et al., 2020). A elevada mobilidade transfronteiriça nessa região, aliada às barreiras impostas pelo limite internacional, pode dificultar o registro de eventos de saúde de importância regional, o que acaba por prejudicar o trabalho da vigilância e o planejamento das ações em saúde. Aliás, a falta de conhecimento preciso sobre a magnitude das populações que vivem e circulam na fronteira, a acessibilidade a seus territórios, a conectividade fluvial e aérea, a capacidade instalada para à atenção em saúde e a capacidade de diagnóstico, entre outros, fragmenta a percepção da dinâmica espacial dos processos socioespaciais transfronteiriços.

Os municípios localizados na linha de fronteira internacional apresentaram maior número de casos confirmados acumulados, destacando-se São Gabriel da Cachoeira-BR (4.974), Lábrea-BR (3.527), Letícia-CO (2.925), Barcelos-BR (2.9 I 8), Ipixuna-BR (2.625), Santa Isabel do Rio Negro-BR (2.356), São Paulo de Olivença-BR (2.109), Tabatinga-BR (2.0I I), Boca do Acre-BR (1.948), e Benjamin Constant-BR (1.779). Além disso, esses municípios apresentaram maior incidência acumulada por 100 mil habitantes (Figura 3), destacando-se Putumayo-PE (40.67 I), Rosa Panduro-PE (38.462), Japurá-BR (21.488), Yaquerana-PE (15.022), Yaguas-PE (14.879), Teniente Manuel Clavero-PE (14.243), São Gabriel da Cachoeira-BR ( 10.917$)$, Barcelos-BR ( 0.610$)$, Santa Isabel do Rio Negro-BR (9.366) e Amaturá-BR (8.955). 
Figura 3 - Taxa de incidência e taxa de mortalidade acumulada de Covid- 19 por município de notificação, na região de fronteira entre Brasil, Colômbia e Peru

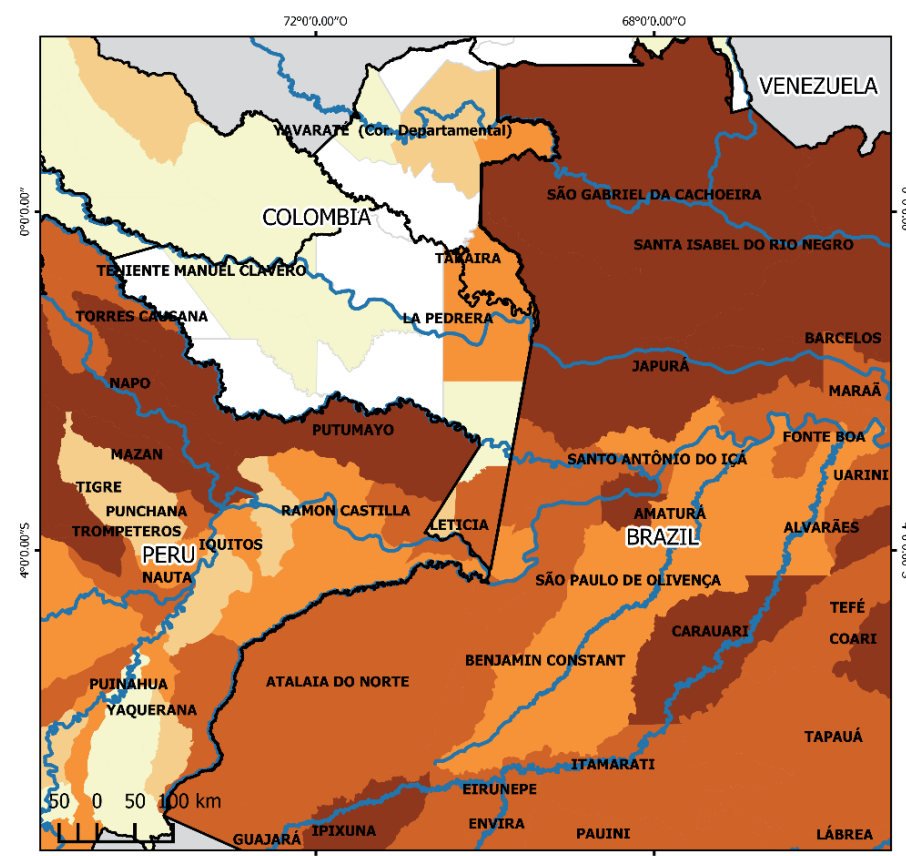

CENÁRIO

EPIDEMIOLÓGICO DE

COVID-19 NA TRIPLICE

FRONTEIRA ENTRE BRASIL, COLOOMBIA E PERU

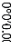
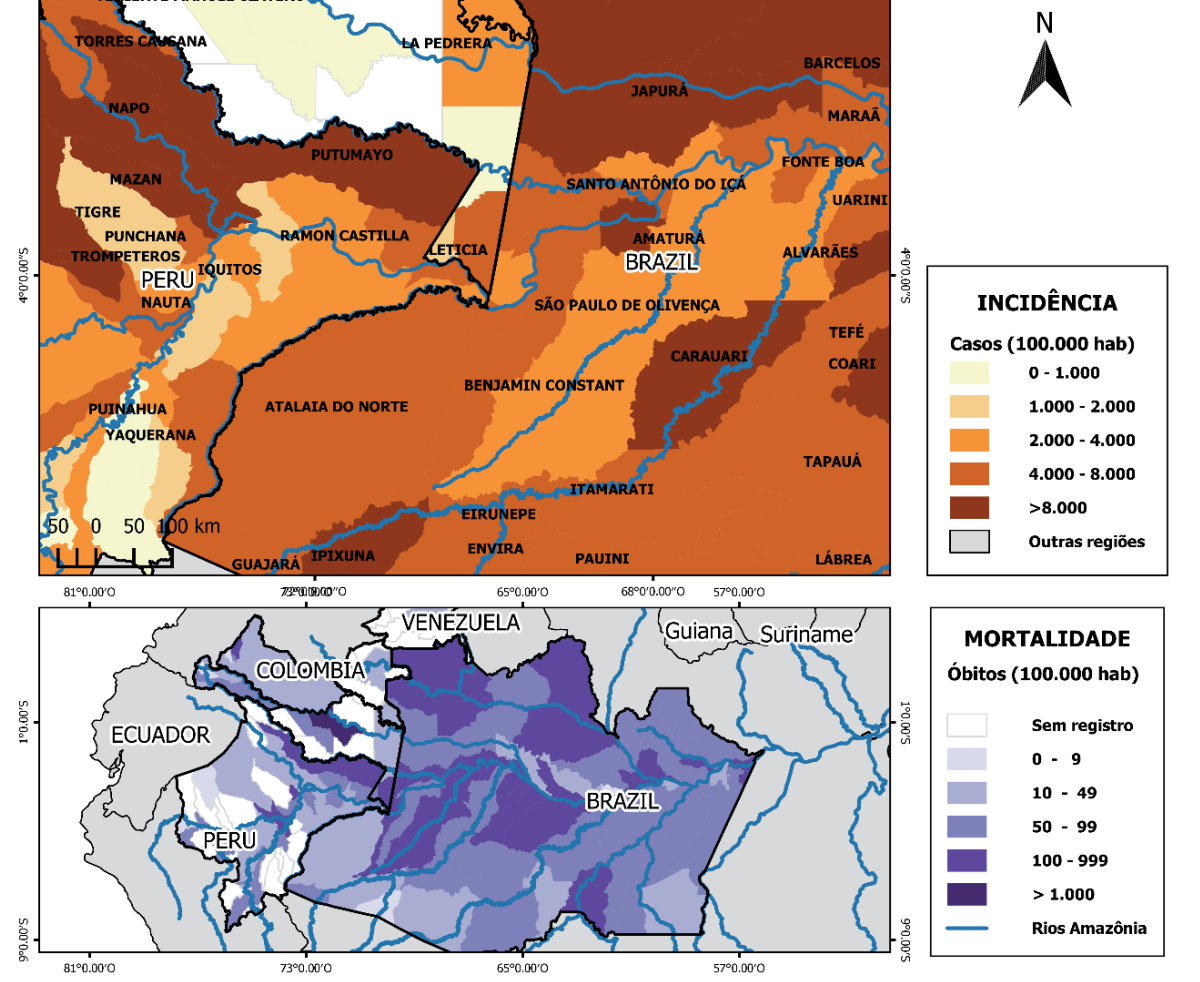

Fontes: Colômbia: VSP Amazonas; Peru: Diresa Loreto; Brasil: Cievs/FVS-AM. Datum Sirgas 2000 (EPSG: 4674). Elaborada por José Joaquín Carvajal Cortés (ILMD/Fiocruz Amazônia) em I 7 dez. 2020.

Quanto à mortalidade, os municípios localizados na faixa de fronteira tiveram maior número de óbitos confirmados acumulado, destacando-se Letícia-CO (I I3), TabatingaBR (87), Puerto Asís-CO (69), São Gabriel da Cachoeira-BR (58), Benjamin Constant-BR (46), Lábrea-BR (44), Mocoa-CO (44), Orito-CO (35), Barcelos-BR (28) e Santo Antônio do Içá-BR (28). Da mesma forma, esses municípios apresentaram maior mortalidade acumulada por 100 mil habitantes, destacando-se Letícia-CO (227), Putumayo-PE 
(136), Tabatinga-BR (132), Santo Antônio do lçá-BR (I 30), São Gabriel da Cachoeira-BR (127), Jutaí-BR (I I 2), Benjamin Constant-BR (107), Jenaro Herrera (106), Puerto AsísCO (103) e Barcelos-BR ( 102) (Figura 3).

A expansão da epidemia para áreas rurais mais afastadas através dos principais rios, tendo como epicentros inicialmente áreas urbanas maiores como Manaus-BR, Letícia$\mathrm{CO}$, Tabatinga-BR, Benjamin Constant-BR e lquitos-PE, possivelmente reflete a alta mobilidade populacional desde as localidades rurais até os principais centros urbanos, e vice-versa, em busca de acesso a serviços básicos e também em razão dos intensos fluxos e intercâmbios de produtos agrícolas e industrializados. Além desses municípios, na fronteira entre Brasil e Colômbia, observaram-se outros epicentros da epidemia: I) São Gabriel da Cachoeira-BR, município com a maior população indígena do Brasil, como epicentro da região Norte na fronteira com os departamentos de Vaupés-CO e Guainia-CO, através dos rios Negro e Vaupés, 2) o município de Japurá-BR, que faz fronteira com a área não municipalizada de La Pedrera-CO, interligados pelo rio Japurá, e 3) o município de Santo Antônio de Içá-BR, interligado com Tarapacá-CO, e as demais áreas não municipalizadas da Colômbia sobre o rio Içá. Na fronteira entre Peru e Colômbia, a alta incidência nos distritos da província de Putumayo-PE, caracterizada por contínuo fluxo de pessoas pelo rio Putumayo, possivelmente levou a doença até as áreas no interior de Puerto Arica, La Chorrera, San Rafael e El Encanto, na Colômbia.

\section{CARACTERIZAÇÃO GENÉTICA DO SARS-COV-2 CIRCULANTE NO ESTADO DO AMAZONAS}

Em março de 2020, o Instituto Leônidas e Maria Deane (ILMD, Fiocruz Amazônia), em parceria com a Fundação de Vigilância em Saúde do Estado do Amazonas (FVS-AM) e o Laboratório Central de Saúde Pública do Amazonas (Lacen-AM), iniciou a caracterização genética do Sars-CoV-2 circulante no estado do Amazonas, Brasil. O primeiro caso analisado foi o de um portador assintomático que retornava de Madri, Espanha, local que vivia uma escalada dramática no número de casos de Covid-19. Por esse motivo, mesmo que se tratasse de caso assintomático, foi realizada a testagem dentro do programa permanente de vigilância de vírus emergentes/reemergentes e negligenciados do ILMD. Após a confirmação do caso foi realizado o sequenciamento do genoma completo do Sars-CoV-2. O processo entre a identificação do caso de infecção, a preparação e o sequenciamento da amostra, e a sua disponibilização para a comunidade científica mundial durou oito dias. Esse primeiro caso foi então confirmado como pertencente à linhagem A.2, com estreita relação filogenética com amostras espanholas, confirmando o vínculo epidemiológico e o nexo temporal (Nascimento et al., 2020). Após o esforço 
para liberar a informação do primeiro genoma do Sars-CoV-2 sequenciado na região Norte do país, os pesquisadores envolvidos nesse projeto se dedicaram, entre abril e maio de 2020, a compor a rede diagnóstica oficial do estado do Amazonas.

O surgimento das linhagens é um processo natural, resultado do acúmulo de mutações ao longo do tempo em que um vírus circula em uma população. Esse processo é mais rápido em vírus de genoma RNA, tal como o Sars-CoV-2, pela falta da atividade de correção da RNA polimerase, enzima responsável pela replicação do material genético, mas também pela grande quantidade de partículas virais produzidas diariamente no hospedeiro. Levando-se em consideração que em uma pandemia milhões de pessoas são infectadas em diferentes locais do mundo, é natural supor que o processo evolutivo culminará com diversas linhagens sendo geradas. Entretanto, a informação contida nos genomas virais serve como ferramenta para a epidemiologia molecular, fornecendo dados cruciais para se entender o caminho que um vírus percorreu até chegar em determinada região. Não obstante, a caracterização genética em larga escala, como vem sendo realizada com o Sars-CoV-2 de maneira sem precedentes na história da humanidade, ajuda a identificar eventuais mutações e suas possíveis consequências. Considerando a evolução do Sars-CoV-2, um grupo de pesquisadores desenvolveu um sistema de classificação em linhagens, tendo como base dois grandes ramos que receberam a denominação de A e B (Rambaut et al., 2020). Assim, à medida que foram surgindo diferenciações genéticas dentro de cada grande ramo, foram sendo designadas linhagens A. I, A.2, B. I, B. I. I, e assim sucessivamente.

Com relação aos dados do Amazonas-BR, até novembro de 2020 foram sequenciados 79 genomas, provenientes de 18 municípios: Anori, Autazes, Careiro, Iranduba, Itacoatiara, Jutaí, Lábrea, Manacapuru, Manaquiri, Manicoré, Maués, Nova Olinda do Norte, Parintins, Presidente Figueiredo, Santa Isabel do Rio Negro, Santo Antônio do Içá e Tabatinga, além da capital Manaus. No total, oito linhagens foram identificadas: A.2; B.I; B.1.1.2; B.1.1.28; B.1.1.33; B.1.1.107; B.1.1.35 e B.1.1.1 II, das quais quatro linhagens (B.I.107; B.I.I I ; B.1.1.2 e B.I.35), que circularam na Dinamarca, Colômbia, Reino Unido e País de Gales, não possuíam registro no Brasil. Com a descoberta dos pesquisadores do ILMD, ao final de novembro de 2020, subiu de 26 para 30 o número de linhagens do Sars-CoV-2 no Brasil, de acordo com os dados disponíveis na plataforma Gisaid, principal banco de dados público com informações genéticas sobre o Sars-CoV-2. 


\section{CONSIDERAÇ̃̃ES FINAIS}

A análise da evolução da epidemia da Covid-I 9 no estado do Amazonas e seus diferentes recortes espaciais permite a construção de hipóteses que venham justificar os diferentes comportamentos de curvas epidêmicas, incluindo aspectos relacionados a fatores locais como a vulnerabilidade e receptividade da área à introdução e reprodução do agente etiológico, bem como aos impactos das medidas de controle ou de contenção da transmissão. A análise dos dados tomando como base a notificação das síndromes respiratórias é uma estratégia importante para uma avaliação que visa a conferir maior sensibilidade do sistema de vigilância local, assim como proporciona a gestão de maior oportunidade na definição ou implementação de medidas para um efetivo controle. A epidemiologia molecular também fornece subsídios essenciais para a compreensão do percurso e dinâmica do vírus nos diferentes recortes geográficos.

A identificação de ao menos oito linhagens do Sars-CoV-2 menos de três meses após o primeiro caso confirmado no Amazonas, Brasil, ressalta a intensidade com que a pandemia chegou nessa região. Dados recentes sobre uma nova variante viral encontrada no Reino Unido, possivelmente mais transmissível, mostra a necessidade do contínuo monitoramento da diversidade genética viral em diferentes regiões do mundo.

O aumento exponencial do número de casos e óbitos por Covid- 19 no Amazonas representou a crise do sistema de saúde diante das desigualdades sociais e das necessidades de saúde da população. Na capital, foi observado o aumento do número de casos da população residente em bairros socioeconomicamente favorecidos, seguido da disseminação dos casos nas áreas periféricas de Manaus, o que nos permitiu sugerir que a doença foi introduzida na capital via aérea em passageiros oriundos de outros países da Europa e da China, uma vez que o polo industrial de Manaus concentra empresas multinacionais com estreita relação comercial com produtos predominantemente chineses. Um terceiro movimento foi o espalhamento do número de casos pelos rios amazônicos em direção ao interior, sem deixar de destacar outros vetores de introdução do vírus via tríplice fronteira e municípios fronteiriços com os estados do Pará, Rondônia, Roraima e Acre, simultaneamente.

A dinâmica epidemiológica da Covid- 19 nessa fronteira mostra como a expansão da Covid-19 para áreas rurais e aldeias indígenas continua sendo motivo de muita preocupação. Porém, as situações de alta vulnerabilidade socioeconômica e desigualdade que as populações amazônicas já vivenciam, intensificadas pela presença de atividades extrativistas e econômicas ilegais, potencializam os problemas de estrutura e acesso aos serviços de saúde. 
Não obstante, vimos a expansão do número de leitos de UTI ocorrer em progressão aritmética, muito aquém do aumento do número de casos confirmados. A taxa de ocupação de leitos exclusivos das redes privada e pública chegou a 90\% e 95\%, respectivamente, ainda em abril de 2020. Não houve preparo da rede assistencial de urgência e emergência de gestões locais anteriores para o enfrentamento ao desafio pandêmico; a ajuda do governo federal, que veio a passos lentos, teria representado o apoio fundamental. À medida que houve provisão oportuna de serviços assistenciais, o sistema de saúde teve capacidade de absorver perturbações e se reorganizar, mediante lições aprendidas com a doença (Fridell et al., 2020). Houve a abertura e fechamento de dois hospitais de campanha (um de gestão municipal e outro estadual), com a expansão de 170 leitos clínicos para casos moderados, 53 dos quais exclusivos para populações indígenas.

O relaxamento das medidas de contenção no processo de evolução da epidemia determinada pelo Sars-CoV-2 é condição importante para o recrudescimento dos níveis epidêmicos e, portanto, deve ser monitorado e criteriosamente planejado. Além da ampliação da vigilância laboratorial para suporte à adequação dos serviços de saúde e à atenção aos pacientes com Srag, políticas públicas que propiciem maior adesão da população às medidas de contenção, como a prática do distanciamento social, isolamento de sintomáticos, investigação e monitoramento de contatos, uso de máscaras, higienização das mãos e de possíveis fômites, devem ser fomentadas em tempo oportuno e avaliadas de maneira contínua.

Concluímos, portanto, que a epidemia no estado e suas fronteiras segue o seu curso em dezembro de 2020, mantendo-se ativa a circulação viral em um importante percentual de população suscetível. Para o ano de 2021, a perspectiva da vacina não deve ser considerada como a solução do problema e, sim como mais uma ferramenta disponível a contribuir para esse objetivo, que representa uma grande conquista civilizatória e a melhor intervenção em saúde pública. Portanto, o uso de máscaras, higienização das mãos e de superfícies críticas, o distanciamento social, isolamento de doentes e monitoramento de contatos, a vigilância transfronteiriça em saúde pública e o fortalecimento da rede de vigilância genômica são medidas ainda imprescindíveis para que se mantenha o controle da situação.

Porém, é imperioso que o Plano Nacional de Imunização do Sistema Único de Saúde (SUS) na região amazônica leve em consideração a sazonalidade do período das chuvas, a disposição populacional ao longo dos rios e lagos e a resiliência dos serviços de saúde de atenção básica e de vigilância atuando de forma integrada. Logo, sugerimos a antecipação do calendário vacinal para os estados da região Norte de abril para fevereiro 
de cada ano, levando em consideração as condições sociais, demográficas e ambientais, uma vez que os primeiros casos de Srag iniciam-se em meados de dezembro e que a informação, necessária para a produção das vacinas, sobre as cepas dominantes na região das Américas é liberada pela OMS em novembro.

\section{REFERÊNCIAS}

AMAZONAS. Decreto n. 4206I, de 16 mar. 2020. Decreta situação de emergência na saúde pública do Estado do Amazonas, em razão da disseminação do novo coronavírus (20 I 9-nCoV), e institui o Comitê Intersetorial de Enfrentamento e Combate ao Covid- I 9. Diário Oficial do Estado, Manaus, 2020a.

AMAZONAS. Portaria n. 25I, de 31 mar. 2020. Institui o Gabinete de Gerenciamento de Crise da Secretaria de Estado da Saúde no Enfrentamento a Covid- I 9 no Amazonas. Diário Oficial do Estado, Manaus, 2020b.

CARVAJAL-CORTÉS, J. J. et al. Dinâmica epidemiológica da pandemia da Covid- I9, na fronteira entre Brasil, Colômbia e Peru; Manaus-AM. Boletim n. 2. Rede Transfronteiriça para o Enfrentamento da Covid-19, 24 jun. 2020. Disponível em: <http://periodicos.uea.edu.br/index.php/ces/issue/ view/138>. Acessado em: 18 dez. 2020.

CAVALCANTE, J. R. et al. Covid- 9 no Brasil: evolução da epidemia até a semana epidemiológica 20 de 2020. Epidemiologia e Serviços de Saúde, 29(4): e2020376, 2020.

FRIDELL, M. et al. Health system resilience: what are we talking about? A scoping review mapping characteristics and keywords. International Journal of Health Policy and Management, 9(1): 6- 16, 2020.

FUNDAÇÃO DE VIGILANCIA EM SAUDE DO AMAZONAS - DRA. ROSEMARY COSTA PINTO (FVSRCP). Boletins epidemiológicos diários da Covid-19. Portal da transparência. Disponível em: <www. fvs.am.gov.br/transparenciacovid I9_dadosepidemiologicos>. Acesso em: 18 dez. 2020.

FUNDAÇÃO OSWALDO CRUZ (FIOCRUZ). InfoGripe. Monitoramento de casos de síndrome respiratória aguda grave (Srag) notificados no Sivep Gripe. Disponível em: < http://info.gripe.fiocruz.br>. Acesso em: 17 dez. 2020a.

FUNDAÇÃO OSWALDO CRUZ (FIOCRUZ). Instituto Leônidas e Maria Deane. Repositório Epidemiológico Transfronteiriço. Disponível em: <https://amazonia.fiocruz.br/?page_id=3|692>. Acesso em: 18 dez. 2020b.

GISAID INICIATIVE. Covid- 19 lineages and variants. Disponível em: <www.gisaid.org >. Acesso em: 17 dez. 2020.

MANAUS. Decreto n. 4.787, de 23 mar. 2020. Declara estado de calamidade pública no município de Manaus para enfrentamento da pandemia do Covid-19, e dá outras providências. Diário Oficial do Município, Manaus, 2020.

NASCIMENTO, V. A. D. et al. Genomic and phylogenetic characterisation of an imported case of Sars-CoV-2 in Amazonas State, Brazil. Memórias do Instituto Oswaldo Cruz, I I 5: I-6, 2020. Disponível em: <www. arca.fiocruz.br/bitstream/icict/4365 I/2/ValdineteANascimento-AndreLGuerra_etal_IOC_2020.pdf>. Acesso em: 17 dez. 2020. 
PÊGO, B. et al. (Orgs.). Fronteiras do Brasil: diagnóstico e agenda de pesquisa para política pública. v. 2. Brasília: Ipea, Ministério da Integração Nacional, 2017.

RAMBAUT, A. et al. A dynamic nomenclature proposal for Sars-CoV-2 lineages to assist genomic epidemiology. Nature Microbiology, 5(I I): I.403-1.407, 2020. Disponível em: <www.nature.com/ articles/s41564-020-0770-5>. Acesso em: 17 dez. 2020.

TOROK, M. Focus on field epidemiology. Epidemic curves ahead. The North Carolina Institute for Public Health. North Carolina Center for Public Health Preparedness, I (5), 2003. Disponível em: <https:// nciph.sph.unc.edu/focus/vol I/issue5/I-5EpiCurves_issue.pdf>. Acesso em: 18 dez. 2020.

WALLINGA, J. \& TEUNIS, P. Different epidemic curves for severe acute respiratory syndrome reveal similar impacts of control measures. American Journal of Epidemiology, I60(6): 509-5 I6, 2004. 